\title{
Intrathoracic meningocele associated with neurofibromatosis Type 1 and a novel technique for surgical repair: case report
}

\author{
Paramita Das, MD, Tarini Goyal, MD, and Matthew A. Hunt, MD \\ Department of Neurosurgery, University of Minnesota, Minneapolis, Minnesota
}

\begin{abstract}
Neurofibromatosis Type 1 (NF1) is a neurocutaneous disorder that can have associated spinal abnormalities related to both bone and dural dysplasia. Thoracic meningoceles are one spine anomaly associated with NF1, although they are a fairly uncommon pathology. Surgical techniques to treat these meningoceles, usually undertaken only when the patient is symptomatic, are targeted at decreasing the size of the protrusion and improving lung capacity. Surgical interventions discussed in the literature include shunting the pseudomeningocele, primary repair with laminectomy, thoracoscopic plication, and reinforcement of the closure with cement, muscle, or fascia. Authors here report the case of a 43-yearold woman with NF1 with worsening pulmonary function tests and in whom shunting of the pseudomeningocele failed. Subsequently, a posterolateral thoracotomy was performed. The dura mater was reconstructed and primarily closed. On this closure a Gore-Tex soft-tissue patch was placed along with polypropylene mesh and Evicel fibrin sealant, followed by titanium mesh. At the end of the procedure, a chest tube was left in place and therapeutic pneumoperitoneum was performed to decrease the dead space as the lung did not fully expand with positive-pressure ventilation. The patient's pulmonary function tests improved after the procedure.
\end{abstract}

Thoracic meningoceles are uncommon and difficult pathologies to treat surgically. Although shunting is arguably the least invasive surgical option, it can fail in some patients. When it does fail, there are other options that require a multidisciplinary approach and careful attention to the dural closure and reinforcing layers.

https://thejns.org/doi/abs/10.3171/2017.2.SPINE16699

KEY WORDS thoracic meningocele; neurofibromatosis Type 1; dural ectasia; surgical technique

$\mathrm{N}$ EUROFIBROMATOSIS Type 1 (NF1) is an autosomal dominant neurocutaneous disorder with complete penetrance, affecting 1 in 3000 individuals among all ethnic groups..$^{13}$ Spinal abnormalities related to both bone and dural dysplasia are seen specifically in NF1, and not in NF2. The incidence of spinal deformities in NF1 ranges from $10 \%$ to $60 \%$, with scoliosis as the most common spinal manifestation. ${ }^{1,4}$ The remainder involve both soft-tissue and osseous complications and include pedicle erosion and enlargement of the intervertebral foramina. Importantly, the dura mater itself is also abnormal.

Dural ectasia refers to widening or outpouching of the dural sac, which can manifest as meningoceles herniating through enlarged intervertebral foramina, scalloping of the vertebral bodies, or erosion of other osseous spinal elements such as the pedicles. The majority of dural ectasias are seen in NF1, but they are also strongly associated with Marfan syndrome. ${ }^{11}$ Other associated conditions include ankylosing spondylitis and achondroplasia, although these may have different mechanisms. ${ }^{23}$ The true pathogenesis behind the dural and bony abnormalities in NF is not known; however, it is thought that underlying mesodermal dysplasia affects both the osseous structures and the dura. ${ }^{15}$ It is also possible that the dural expansion puts stress on surrounding bone, contributing to the scalloping and thinning of the pedicles.

Thoracic meningoceles associated with NF1 were first described in 1933 by Phol..$^{18}$ Overall, it is an uncommon pathology, but $69 \%$ of thoracic meningoceles are associated with NF1. ${ }^{5}$ In the thorax, lateral meningoceles are more common because the paravertebral muscles are relatively weak and the pressure gradient between the cerebrospinal

ABBREVIATIONS CSF = cerebrospinal fluid; NF1 = neurofibromatosis Type 1; PEEP = positive end-expiratory pressure.

SUBMITTED September 16, 2016. ACCEPTED February 9, 2017.

INCLUDE WHEN CITING Published online June 16, 2017; DOI: 10.3171/2017.2.SPINE16699. 


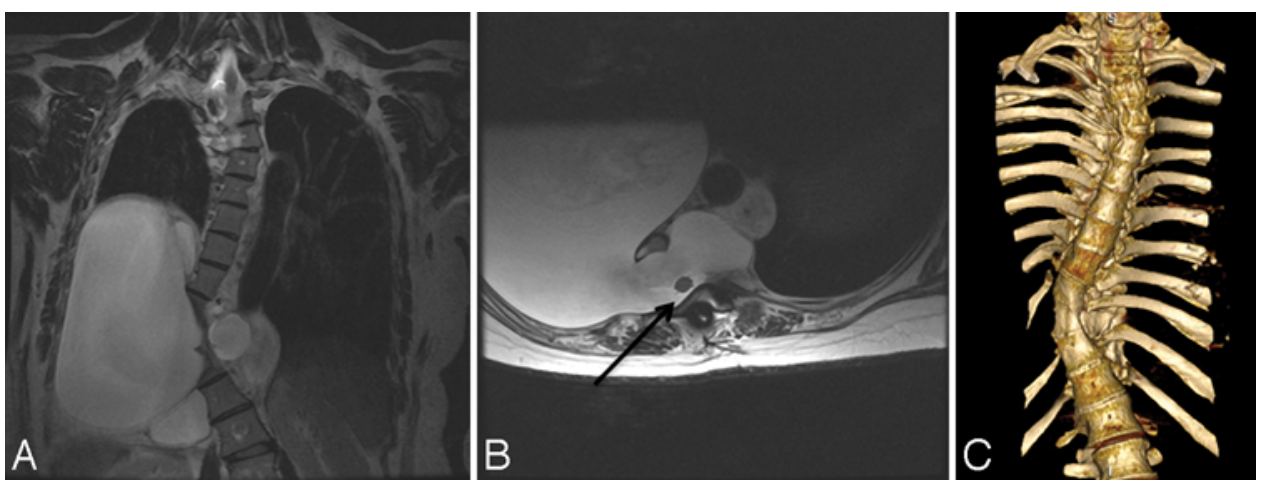

FIG. 1. A: Coronal T2-weighted MR image of the thorax showing a large right-sided pseudomeningocele taking up more than $50 \%$ of the chest cavity. B: Axial T2-weighted MR image of the dilated neuroforamen (arrow) with a large connection between the thecal sac and pseudomeningocele. C: Reconstruction CT demonstrating scalloping of the vertebral bodies. Figure is available in color online only.

fluid (CSF) space and the pleural space is higher. ${ }^{14}$ Often there is an associated kyphoscoliotic deformity of the thoracic spine. ${ }^{5,6}$ Pseudomeningoceles have been reported in the cervical and lumbar spine as well; however, they are fairly uncommon..$^{9,12}$

Meningoceles can be asymptomatic or present with neurological or pulmonary findings. They can cause paraparesis, pain from compression of the spinal cord, or lowpressure headaches. There may also be compression of the lung cavity or mediastinal structures, which can cause cough, dyspnea, and palpitations. ${ }^{17}$ Surgical techniques to treat these meningoceles, usually undertaken only when the patient is symptomatic, are targeted at decreasing the size of the protrusion and improving lung capacity.

\section{Case Report}

\section{History and Examination}

A 43-year-old woman was initially diagnosed with NF1 at the age of 9 after she had presented with scoliosis. She underwent spinal fusion with Harrington rod placement at the age of 12 and was lost to follow-up. She presented to us with back pain and dyspnea that had been progressive for the past 2 years. On examination, she was neurologically intact with scoliosis. Significant restrictive lung disease was present, with pulmonary function tests at $38 \%$ of ageadjusted normal. Magnetic resonance imaging of the spine and CT scanning of the chest showed a large right thoracic meningocele, along with dystrophic changes and scalloping of the midthoracic spine from T-8 to T-11 (Fig. 1).

\section{First Treatment}

As initial treatment, we placed a cystoperitoneal shunt with a programmable Strata valve (Medtronic) adjusted to a pressure of 0.5. Because of low-pressure headaches, the valve was eventually adjusted to 2.0 . The patient also seemed to have neck pain as a symptom of overdrainage that resolved with increasing the shunt valve setting. The thoracic meningocele did not change in size, pulmonary function tests did not improve, and the patient did not report relief of her dyspnea. Two large-volume taps of the shunt at $1 \mathrm{~L}$ and $1.2 \mathrm{~L}$ on 2 separate occasions, as well as changing the pressure setting of the valve down to
1.0 , were attempted without improvement in the patient's symptoms. Immediately after these taps, the volume of the pseudomeningocele would be smaller on imaging but the fluid would reaccumulate (Fig. 2).

\section{Second Treatment}

Since the patient did not improve, a right posterolateral thoracotomy with resection of the meningocele and reconstruction of the dural sac was performed with the assistance of a thoracic surgeon. At the seventh intercostal space, the large dural sac was drained and found to contain nearly $2 \mathrm{~L}$ of CSF. The spinal cord was identified prior to resection of the sac (Fig. 3). The dura was closed primarily using silk sutures, and a polypropylene mesh was used to reinforce the repair. Evicel (Ethicon Inc.), a fibrin-based dural sealant, was also applied. Valsalva maneuvers were used to confirm the absence of a CSF leak, and closure was performed with the assistance of the thoracic surgeons and a chest tube was left in place. Lumbar drainage was used postoperatively for 7 days, and the patient was kept on bed rest.

\section{Third Treatment}

Because of persistent filling of the pseudomeningocele, the patient was taken back to the operating room for repeat repair of the meningocele. Endotracheal intubation was
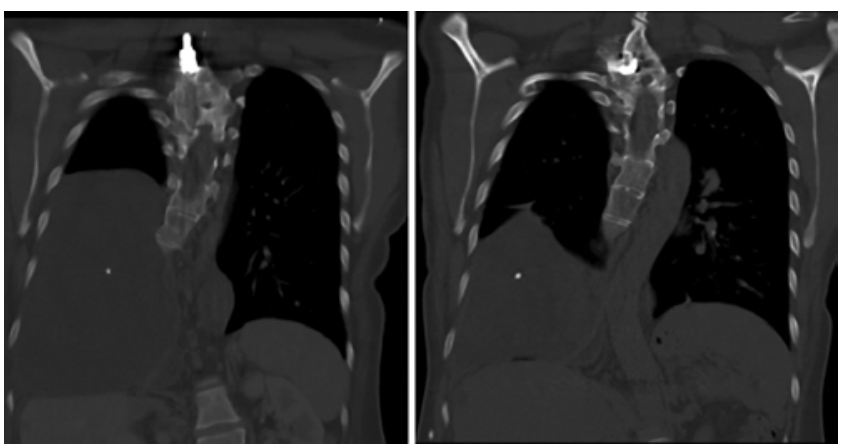

FIG. 2. Comparison of the pseudomeningocele before (left) and after (right) a shunt tap, confirming a functioning shunt and temporarily decreasing fluid collection. 


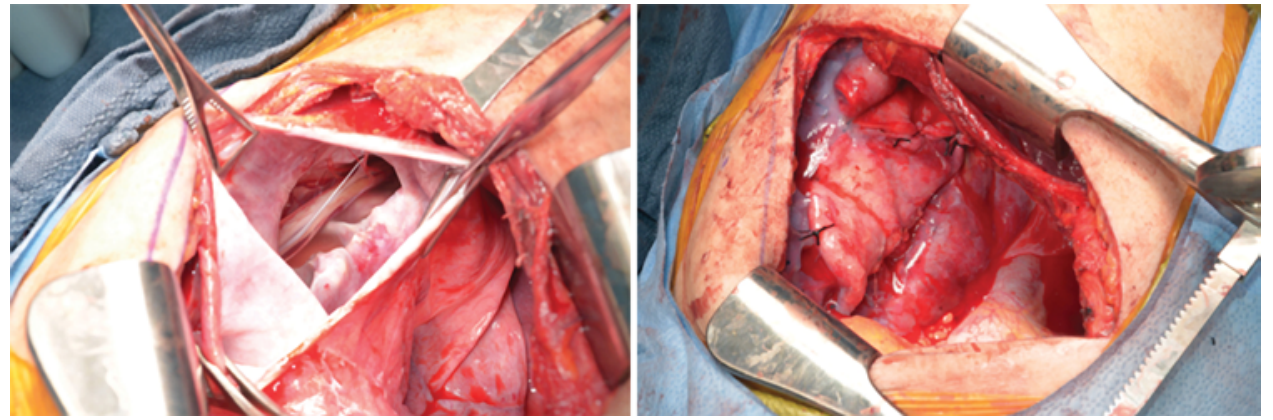

FIG. 3. Left: Photograph obtained during the first thoracotomy during which the dural sac was opened, the spinal cord was identified, the sac was resected, and the dura was closed with silk sutures. Right: Photograph obtained prior to placement of the mesh. Figure is available in color online only.

achieved with a double lumen tube to allow for single lung ventilation when repairing the pseudomeningocele. The thoracotomy was reopened, and the dura again closed primarily. A Gore-Tex soft-tissue patch (Gore Medical) was placed over the repair and Evicel was applied. Over this, polypropylene mesh was placed and Evicel was reapplied. Over this, a piece of titanium mesh was secured with a cranial plating system (DePuy Synthes CMF system) and Evicel was reapplied. Initially to promote expansion of the lung, a positive end-expiratory pressure (PEEP) of $10 \mathrm{~cm} \mathrm{H}_{2} \mathrm{O}$ was used with sustained high peak pressures. Although this resulted in some reexpansion, the dead space was not resolved and therefore therapeutic pneumoperitoneum was performed. One of the problems in a hydropneumothorax is that there is a larger pleural space because there is a reduction in lung volume in relation to chest cavity volume. The introduction of air into the peritoneal cavity displaces the diaphragm cephalad and decreases the volume of the chest cavity relative to lung volume. ${ }^{19}$

To perform the pneumoperitoneum, a purse-string suture was placed in the diaphragm. The diaphragm was then opened, and a 14-Fr red rubber catheter was placed into the peritoneum. The pneumoperitoneum was created by insufflating the abdomen with $2.5 \mathrm{~L}$ of air and monitoring airway pressures, blood pressure, and urine output. The defect in the diaphragm was sutured shut. Two chest tubes and a lumbar drain were placed.

\section{Postoperative Course}

The patient remained intubated on a PEEP of $10 \mathrm{~cm}$ $\mathrm{H}_{2} \mathrm{O}$ for 24 hours to promote lung reexpansion. Her chest tubes were weaned over 10 days, and the lumbar drain was removed on the 11th day after surgery. She recovered well, and postoperative pulmonary function tests showed an improvement to $50 \%$ of age-adjusted normal. Imaging 1 year after her procedure showed a decrease in the size of the pseudomeningocele (Fig. 4).

\section{Discussion}

Surgical intervention is indicated when a meningocele has a rapid rate of growth or when a patient is symptomatic due to compression of surrounding structures. ${ }^{21}$ The earliest surgical treatments involved posterior laminectomy with direct repair of the meningocele. However, laminec- tomy is contraindicated for severe kyphoscoliosis as it can accelerate progression of spinal deformity. ${ }^{10}$ Some suggest that if scoliosis is present, the patient may need extensive posterior fusion and anterior stabilization.

There have also been reports on the placement of cystoperitoneal and lumboperitoneal shunts using fixed pressure $^{24}$ and programmable valves. ${ }^{7,22}$ However, this is not always a definitive treatment, and open surgery should be considered if there is no clinical improvement, as demonstrated in our patient. It is also possible that a patient presenting with low-pressure headaches will not have improvement in the headaches with a shunt.

When there is a large meningocele, thoracotomy is preferred. Watertight closure of the dura in these cases is difficult and postoperative fistulas can occur. ${ }^{16}$ There have been reports of closures that have been reinforced with cyanoacrylate cement, ${ }^{8}$ muscle, or fascia. ${ }^{20}$ As demonstrated in our patient, Gore-Tex or mesh may be another option for reinforcing the closure. It is unlikely that primary repair alone would be successful in these patients because of the inherent abnormalities in the dura; however, thoracoscopic plication has been successful. ${ }^{3}$

A posterolateral extradural approach has some advantages over an open thoracotomy. It does not require chest tube drainage, which can be advantageous as the dural repair may not be completely watertight. This technique may not be suitable for very large intrathoracic meningoceles as the resected dural sac may not be able to be removed without the spread or resection of the ribs, particu-
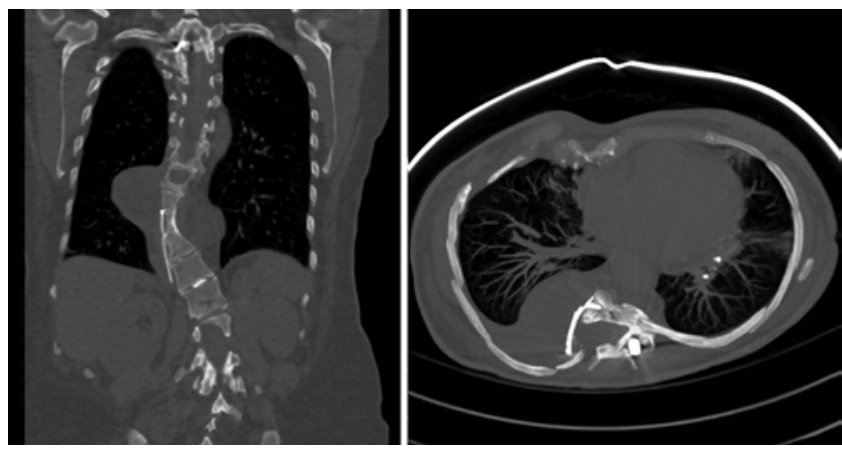

FIG. 4. One-year postoperative coronal and axial CT scans showing a small residual pseudomeningocele (left) and mesh repair in place (right). 
larly in a case in which the meningocele involves several vertebral levels. ${ }^{2}$

\section{Conclusions}

Thoracic meningoceles are uncommon and a difficult pathology to treat surgically. Although shunting is arguably the least invasive surgical option, it can fail in some patients. When it does fail, there are more invasive options that require a multidisciplinary approach and careful attention to the dural closure and reinforcing layers. Here, we have presented a successful result in a patient in whom initial shunt placement had failed.

\section{References}

1. Akbarnia BA, Gabriel KR, Beckman E, Chalk D: Prevalence of scoliosis in neurofibromatosis. Spine (Phila Pa 1976) 17 (8 Suppl):S244-S248, 1992

2. Chee CP: Posterolateral extradural approach for total excision of lateral thoracic meningocele: technical report. Neurosurgery 21:749-751, 1987

3. Chen HC, Chang PH, Jhang SW, Wang BY: Thoracoscopic plication for a huge thoracic meningocele in a patient with neurofibromatosis. J Cardiothorac Surg 9:85, 2014

4. Crawford AH, Parikh S, Schorry EK, Von Stein D: The immature spine in type-1 neurofibromatosis. J Bone Joint Surg Am 89 (Suppl 1):123-142, 2007

5. de Andrade GC, Braga OP, Hisatugo MK, de Paiva Neto MA, Succi E, Braga FM: Giant intrathoracic meningoceles associated with cutaneous neurofibromatosis type I: case report. Arq Neuropsiquiatr 61 (3A):677-681, 2003

6. Del Buono MS, Oscar EM: Intrathoracic meningocele associated with cutaneous neurofibromatosis. Acta Neurochir (Wien) 9:561-580, 1961

7. Dinichert A, Cornelius JF, Lot G: Lumboperitoneal shunt for treatment of dural ectasia in ankylosing spondylitis. J Clin Neurosci 15:1179-1182, 2008

8. Dolynchuk KN, Teskey J, West M: Intrathoracic meningocele associated with neurofibromatosis: case report. Neurosurgery 27:485-487, 1990

9. Drevelengas A, Kalaitzoglou I: Giant lumbar meningocele in a patient with neurofibromatosis. Neuroradiology 37:195197, 1995

10. Ebara S, Yuzawa Y, Kinoshita T, Takahashi J, Nakamura I, Hirabayashi $\mathrm{H}$, et al: A neurofibromatosis type 1 patient with severe kyphoscoliosis and intrathoracic meningocele. J Clin Neurosci 10:268-272, 2003

11. Fattori R, Nienaber CA, Descovich B, Ambrosetto P, Reggiani LB, Pepe G, et al: Importance of dural ectasia in phenotypic assessment of Marfan's syndrome. Lancet 354:910913, 1999

12. Freund B, Timon C: Cervical meningocoele presenting as a neck mass in a patient with neurofibromatosis 1 . J Laryngol Otol 106:463-464, 1992
13. Friedman JM: Epidemiology of neurofibromatosis type 1 . Am J Med Genet 89:1-6, 1999

14. Jeong JW, Park KY, Yoon SM, Choe W, Kim CH, Lee JC: A large intrathoracic meningocele in a patient with neurofibromatosis-1. Korean J Intern Med 25:221-223, 2010

15. Khoo Bao JN, Ogunwale B, Huson SM, Ealing J, Whitehouse RW: Spinal bone defects in neurofibromatosis type I with dural ectasia: stress fractures or dysplastic? A case series. Eur Radiol 23:3418-3421, 2013

16. Maiuri F, Corriero G, Giampaglia F, Simonetti L: Lateral thoracic meningocele. Surg Neurol 26:409-412, 1986

17. Oner AY, Uzun M, Tokgöz N, Tali ET: Isolated true anterior thoracic meningocele. AJNR Am J Neuroradiol 25:18281830,2004

18. Phol R: Meningocele in brustraum unter dem bilde eines intra-thoraken brandschatten. Rontgenpraxis 5:747-749, 1933

19. Podgaetz E, Berger J, Small J, Garza R, Andrade R: Therapeutic pneumoperitoneum: relevant or obsolete in 2015 ? Thorac Cardiovasc Surg [epub ahead of print], 2016

20. Rainov NG, Heidecke V, Burkert W: Thoracic and lumbar meningocele in neurofibromatosis type 1 . Report of two cases and review of the literature. Neurosurg Rev 18:127-134, 1995

21. Sakamoto H, Hoshino A, Ito K, Sakuraya M, Sato M, Sawada Y, et al: Intrathoracic giant meningocele associated with neurofibromatosis. Intern Med 42:767-768, 2003

22. Tanaka K, Shimizu K, Kakegawa S, Oshima K, Takeyoshi I: Cystoperitoneal shunt for a giant intrathoracic meningocele under local anesthesia. Ann Thorac Surg 91:317-319, 2011

23. Toyoda K, Taguchi T, Kaneko K, Kato Y, Imajo Y, Imagama T: High-grade L5 spondylolisthesis associated with dural ectasia in neurofibromatosis. J Orthop Sci 10:233-236, 2005

24. Vanhauwaert DJ, Deruytter MJ: Cystoperitoneal shunt as alternative treatment for a giant thoracic meningocele in a patient with neurofibromatosis. Surg Neurol 69:535-537, 2008

\section{Disclosures}

Dr. Hunt is a consultant for DePuy Synthes.

\section{Author Contributions}

Conception and design: Das. Analysis and interpretation of data: Goyal. Drafting the article: all authors. Critically revising the article: Das, Hunt. Reviewed submitted version of manuscript: Das. Approved the final version of the manuscript on behalf of all authors: Das. Study supervision: Hunt.

\section{Correspondence}

Paramita Das, Department of Neurosurgery, University of Minnesota, D429 Mayo Memorial Bldg., 420 Delaware St. SE, MMC 96, Minneapolis, MN 55455. email: dasxx092@umn.edu. 